\title{
Movember update: The Canadian perspective
}

\author{
Michael Jeffcott, ${ }^{*}$ llias Cagiannos MD, FRCSC, ${ }^{\dagger}$ Kevin C. Zorn, MD, FRCSC, FACS \\ *Movember, 2012 Montreal Committee Co-Chair, Montreal, QC; † Division of Urology, University of Ottawa, Ottawa, ON; ;University of Montreal Hospital Centre, Montreal, QC
}

Cite as: Can Urol Assoc J 2012;6(3):E111-E114. http://dx.doi.org/10.5489/cuaj.12037

T his past November, one could not help but notice that a disproportionate number of men were sporting what had become a style of generations past - the moustache. Just last year, for many Canadians, the phenomenon known as Movember was a relative mystery. Now even before Movember (the month formerly known as November) begins, it's hard not to hear or see something about it.

While the oldest known image of a man with a moustache is a Scythian horseman from 300 BC, recently the moustache had become a preposterous fashion statement to some. Times change quickly; for the moustache, they have changed again. Movember, a charity seeking to "change the face of men's health," has begun to change men's faces. The impact the foundation is having on men's health is only beginning.

In 2003, a few friends sat in a pub in Melbourne, Australia, chatting about outdated styles and trends. Like many great ideas, a whimsical comment about bringing back the moustache led to a month-long growing challenge and Movember (the combination of the Australian slang for moustache, "Mo" and November) was born, cofounded by Travis Garone, Luke Slattery, Justin Coughlin and Adam Garone. The rules were simple: start on November 1st cleanshaven and spend the remainder of the month growing a moustache. Only 30 people participated that year, but the growers were overwhelmed by the interest. Having realized the potential for their contest, Movember's founders began to seek a cause to support. Inspired in part by the women's health movement, they recognized that men were lacking a way to get involved in their own health matters.

The following year, the group increased to a staggering 450 participants and the campaign evolved. It focused on raising funds for men's health issues in general, and the number one cancer affecting men in particular, prostate cancer. That year, the small group raised $\$ 55000$ for the Prostate
Cancer Foundation of Australia. It was the single largest donation the foundation had ever received.

In 2006, awareness-building and education related to men's health issues officially took their places as paramount campaign elements alongside fundraising, with the ambition of reducing preventable male deaths. The reasons for the current state of men's health are numerous and complex, but according to Movember, one of the issues is the way men think about their health. Movember's awareness and education program is focused on helping men get comfortable with the notion of talking about their health and on putting men's preventive health on the radar.

In 2007, the charity moved overseas and established official campaigns in the United States, the United Kingdom, Spain and Canada. The Canadian foundation, currently headed by Pete Bombaci, National Director, is based in Toronto. In our very first year, Canadians helped raise \$545 000 . Movember Canada's primary beneficiary is Prostate Cancer Canada, which allocates funds and manages programs. This past November was the 5th Movember campaign in Canada. Canadians can be proud that, in 2011, Canada was the \#1 fundraising country in the world, surpassing Australia itself, with roughly $\$ 41$ million dollars raised by nearly a quarter of a million participants (Table 1 ).

From its humble beginnings less than 10 years ago, Movember has grown remarkably to become a truly global movement, inspiring more than 1.1 million registered participants known as "Mo Bros" and "Mo Sistas" thus far (Fig. 1).

The success of Movember can be attributed, at least partially, to the unique ideology of the campaign. Since 2003, it has maintained its grassroots approach. From its modest beginning (when the four founders donated the resources required to run the campaign), Movember continues to rely on its participants for its success (Fig. 2). Advertising and marketing for Movember is less about television, radio and internet marketing and more about people in the community 
Jeffcott et al.

\begin{tabular}{|c|c|c|}
\hline Country & Registrations & Amount raised (CAD) \\
\hline Canada & 246,642 & $\$ 41,184,234$ \\
\hline United Kingdom & 253,549 & $\$ 29,985,815$ \\
\hline Australia & 142,268 & $\$ 28,177,867$ \\
\hline United States & 144,730 & $\$ 14,650,322$ \\
\hline Ireland & 15,474 & $\$ 2,217,316$ \\
\hline New Zealand & 13,149 & $\$ 1,182,400$ \\
\hline South Africa & 17,958 & $\$ 594,038$ \\
\hline Netherlands & 3,311 & $\$ 354,330$ \\
\hline Norway & 3,823 & $\$ 267,009$ \\
\hline Denmark & 7,643 & $\$ 205,162$ \\
\hline Finland & 2,870 & $\$ 97,315$ \\
\hline Belgium & 747 & $\$ 74,548$ \\
\hline Czech Republic & 1,450 & $\$ 30,935$ \\
\hline Spain & 1,233 & $\$ 30,651$ \\
\hline $\begin{array}{l}\text { Total for all } \\
\text { countries }\end{array}$ & 854,847 & $\$ 119,051,945$ \\
\hline
\end{tabular}

who are changing their appearances and becoming walking, talking billboards for the cause. Men might not be inclined to wear ribbons or give up their Sundays for runs, but donating their appearance for a month, while giving in to childhood Doc Holliday or Lanny McDonald daydreams, is another story all together.

By discussing their moustaches and the unique challenges men face with their health, the moustachioed walking billboards disseminate vital information about prostate cancer wherever they go. To do so, they are supported by a comprehensive official Movember website (ca.movember.com). Through the site, registrants and visitors can learn about

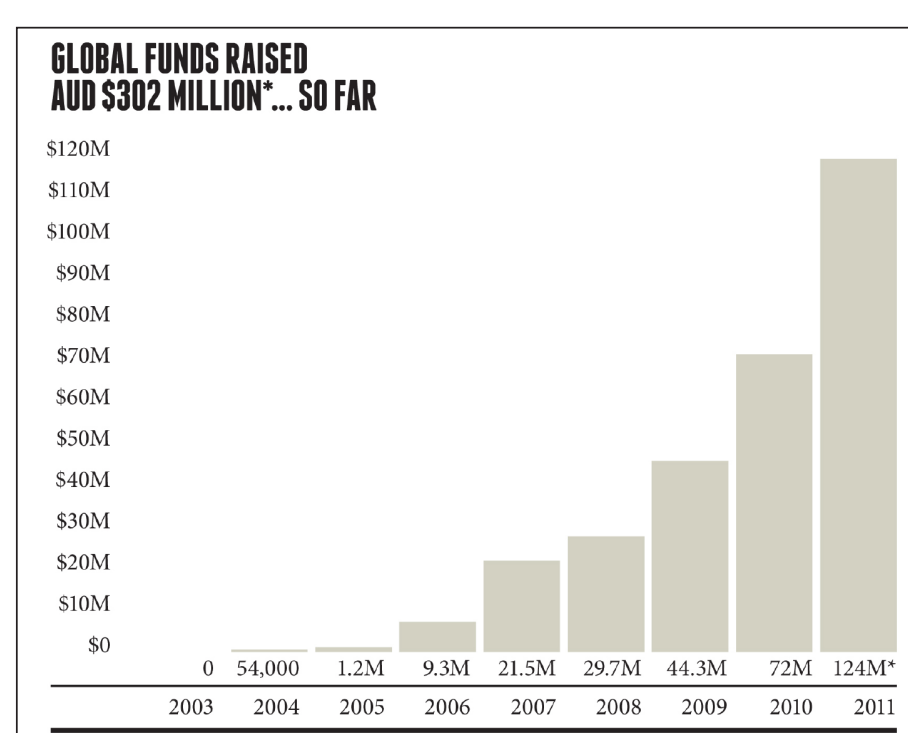

${ }^{{ }^{*}}$ Funds raised are an interim figure correct at time of publishing. Audited financials will be published at movember.com in August 2012. Funds shown on this graph are in AUD. men's health, make donations and surf a vast collection of stories and pictures from the participants themselves. Social media and viral advertising also help spread the word. The result is a highly effective word-of-mouth campaign, as well as a strong feeling of belonging to a greater group comprised of both those whom have lived through the disease and others supporting those enduring treatment.

Moreover, there are also official Movember events, such as the closing "Gala Partés", the celebrations at month's end, which have taken on a life of their own. Every level of society is represented, from the casual participant to public figures, such as federal Member of Parliament Justin Trudeau (who is a Movember captain on Parliament Hill, where more than half the elected MPs, spanning party lines, take part in the campaign). People in their twenties and thirties are especially well-represented, further promoting a goal of the campaign: to have people become more aware of the risks and have themselves checked earlier in life rather than later.

Very low operating costs are another positive result of the grassroots philosophy. Taking the 2010 campaign as an example, \$22.3 million in funds were raised in Canada alone. Of that $\$ 22.3$ million, $88 \%$ was allocated to programs. More specifically, $86 \%$ went to prostate cancer research and survivor support programs run by Prostate Cancer Canada, and $2 \%$ went to Movember's awareness and education program. What becomes obvious is that only $12 \%$ of funds raised are allocated to administrative and fundraising costs, while international best practice standards typically range from $15 \%$ to $25 \%$.

One of the most momentous achievements funded significantly through Movember was the first construction of a complete genetic map of prostate cancer (http:// us.movember.com/about/beneficiary1 - Whole Genome

\section{GLOBAL REGISTRANTS 1.9 MILLION MO BROS \& MO SISTAS... SO FAR}

900,000

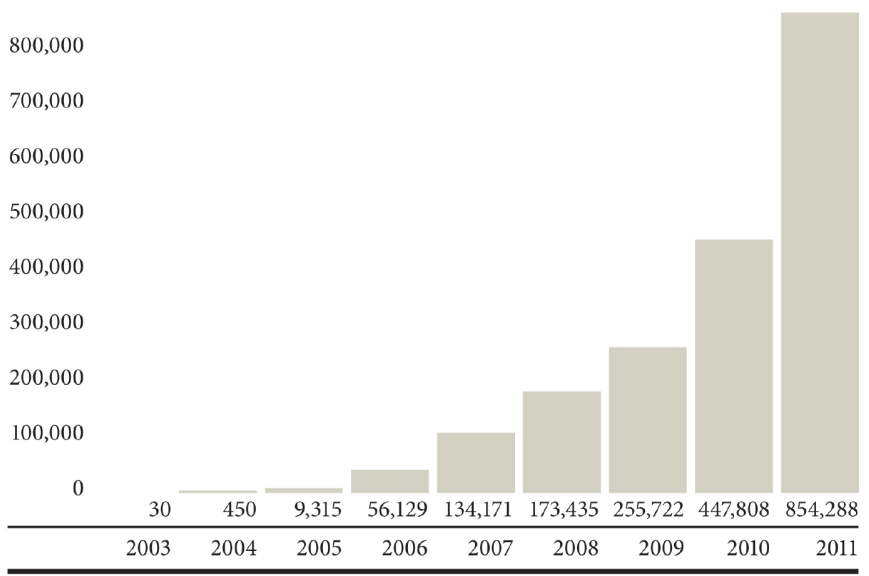

Fig. 1. Annual Movember global fundraising totals since 2003 inception. Graph courtesy of Movember Canada http://ca.movember.com/about/. 


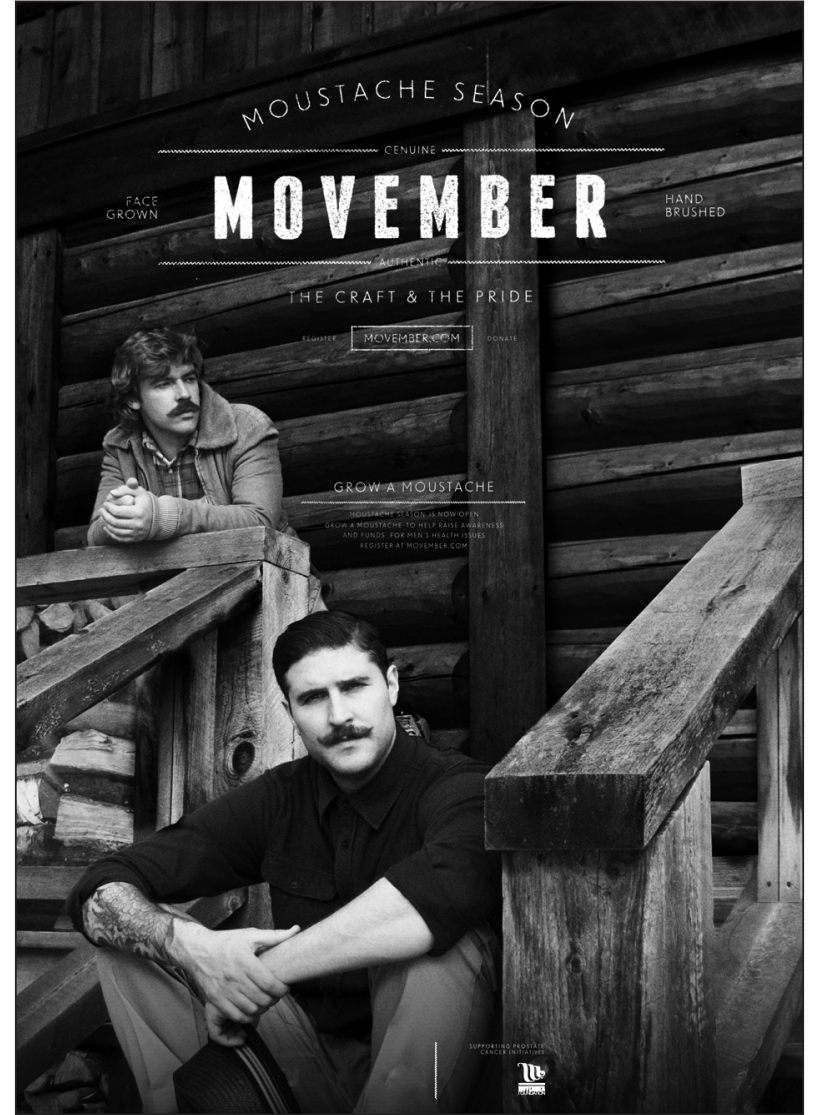

Fig. 2. Official Movember 2011 Campaign Poster highlighting the Moustache as the driving visual slogan for prostate cancer awareness and men's health.

Sequencing Program). A historic breakthrough, the blueprint will increase the understanding of how the disease works by identifying changes or mutations in the DNA sequences and distinguishing genetic damage that spurs prostate cancer, leading to improved and more personalized treatment. Information gathered about mutations in these DNA sequences should help advance disease detection, assess tumour aggressiveness and identify optimal treatments based on individual patient needs. It will also assist in tailoring prostate cancer medicine to specific cases. While far from a cure, this step in the fight also will help doctors determine which cancers are likely to kill quickly, requiring immediate attention, and which are likely to be less aggressive and can be managed by active surveillance, with less impact on one's quality-of-life. Researchers also expect that the gene program will stimulate the development of new cancer drugs.

The gene mapping project brings scientists from all over the world together to collaborate on a mission of global scale. However, Movember also funds on the national level, with the money raised going specifically to Prostate Cancer Canada. Researchers at the University of Victoria have benefitted from this philosophy, recently receiving funding for two such projects. Researchers are attempting to develop protein-protein interaction inhibitors which aim to block novel pathways not targeted by current therapeutic approaches. The other Movember-funded research project investigates the ability of antibody-bound nanoparticles to enhance magnetic resonance imaging visualization of prostate cancer. Other applications involve laser light illumination of the nanoparticles to allow for intra-operative visualization of cancer.

Funding of research projects of various scopes is complemented by infrastructure funding as well, fulfilling two of Movember's initiative: helping to find a cure as well as survivorship care and education. One such example is a new prostate cancer clinic in Edmonton. The many benefits of the centre respect Movember's integrated approach to the search for a cure. It will be a central access point providing care, education, treatment and support from screening and diagnosis to recovery. The multimillion dollar clinic, expected to be completed in 2012, and the associated Rapid Access Prostate Health Clinic, which is expected to open in 2013, received \$1.0 million through Movember.

These are some examples of the diverse and important projects funded in large part by the Movember campaign. The effect of the money raised by growing moustaches is simply astonishing. This impact includes other programs and projects funded by Prostate Cancer Canada, such as the Pilot Grant Program, which provides funding to high-potential pilot studies, or the Clinician-Scientist Program, which provides salaries and research support for applied researchers beginning their careers as independent investigators and junior faculty in prostate cancer research, or the contribution to comprehensive survivor support programs which include the current Prostate Cancer support groups nationwide.

Looking forward, the Movember Foundation is continuing its fast-paced growth, maintaining its core principles and, now, expanding to formally bring together researchers from around the globe with the Movember Foundation Global Action Plan (GAP). This is a unique initiative which aims to accelerate prostate cancer research results through global collaboration. The international presence of Movember makes the foundation distinct in its ability to address the challenge. The GAP will complement existing programs run by Movember's beneficiary partners around the world. The goal is not just to fund collaborative global research, but also to share all data freely with the entire prostate cancer community. Over time, the sharing of data among all the projects will help researchers avoid unnecessary duplication of effort and deliver greater returns on the funds which Movember and other organizations invest in prostate cancer research.

To effectively drive the GAP initiative, Movember's board of directors has established an independent Global Scientific Committee (GSC) comprised of some of the very best prostate cancer experts from around the world. The GSC's role will be to advise the board on what research programs are 
Jeffcott et al.

the most deserving of funding, and how the funding should be implemented. This process will facilitate global research collaboration projects and increase the efficiency of prostate cancer research.

Movember is also creating Promoveo, a global, online community for prostate cancer researchers, clinicians and organizations. Tailored specifically to the needs of the prostate cancer research community, Promoveo will let members share ideas, find out what key research resources are available in other countries, post information to foster discussion, and connect with other researchers from across the globe.

Throughout the foundation's dramatic expansion, Movember encourages men to see their doctors and promote discussions, using the moustache as an ice-breaker. It should be noted that the campaign also promotes values associated with traditional gentlemanliness, if the rest wasn't already enough.

Movember is a remarkable story which, while it is in its infancy, promises a future which is very encouraging. There is significant growth in the movement year after year and Canada is an enthusiastic Movember adopter. For everyone in the field, locally and globally, this means a significant increase in funding, collaborative possibilities and awareness, immediately and for years to come. To get involved with Movember or to learn more about projects and funding in your area, contact Movember (info.ca@movember.com) or Prostate Cancer Canada (Stuart.edmonds@prostatecancer.ca).

Competing interests: None declared.

This paper has been peer-reviewed.

Correspondence: Dr. Kevin C. Zorn, Assistant Professor, University of Montreal Hospital Centre, 235 boul. Rene Levesque East, Suite 301, Montreal, QC H2X 1N8; fax: 514-861-3021; zorn.chumurology@gmail.com 